\title{
Pioglitazone is equally effective for diabetes prevention in older versus younger adults with impaired glucose tolerance
}

\author{
Sara E. Espinoza - Chen-pin Wang • Devjit Tripathy • Stephen C. Clement • \\ Dawn C. Schwenke • Mary Ann Banerji • George A. Bray • Thomas A. Buchanan • \\ Robert R. Henry • Abbas E. Kitabchi • Sunder Mudaliar • Frankie B. Stentz • \\ Peter D. Reaven • Ralph A. DeFronzo • Nicolas Musi
}

Received: 9 May 2016 / Accepted: 19 August 2016/Published online: 1 September 2016

(C) The Author(s) 2016. This article is published with open access at Springerlink.com

\begin{abstract}
To determine the efficacy of pioglitazone to prevent type 2 diabetes in older compared to younger adults with pre-diabetes. Six hundred two participants with impaired glucose tolerance (IGT) were randomized in double blind fashion to placebo or pioglitazone for
\end{abstract}

Electronic supplementary material The online version of this article (doi:10.1007/s11357-016-9946-6) contains supplementary material, which is available to authorized users.

\author{
S. E. Espinoza $(\bowtie) \cdot$ C.-p. Wang $\cdot$ N. Musi $(\bowtie)$ \\ Barshop Institute for Longevity and Aging Studies, University of \\ Texas Health Science Center at San Antonio, 7703 Floyd Curl \\ Drive, San Antonio, TX 78223, USA \\ e-mail: espinozas2@uthscsa.edu \\ e-mail: musi@uthscsa.edu \\ S. E. Espinoza $\cdot$ C.-p. Wang $\cdot$ N. Musi \\ Geriatrics Research, Education and Clinical Center, South Texas \\ Veterans Health Care System, 7400 Merton Minter Blvd., San \\ Antonio, TX 78229, USA \\ D. Tripathy $\cdot$ R. A. DeFronzo $\cdot$ N. Musi \\ Texas Diabetes Institute, University of Texas Health Science \\ Center at San Antonio, 7703 Floyd Curl Dr, San Antonio, TX \\ 78229, USA \\ D. Tripathy · R. A. DeFronzo \\ South Texas Veterans Health Care System, 7400 Merton Minter \\ Blvd., San Antonio, TX 78229, USA

\section{S. C. Clement} \\ Department of Medicine Division of Endocrinology and \\ Metabolism, Georgetown University, 3700 O St NW, Washington, \\ DC 20057, USA \\ D. C. Schwenke \\ Arizona State University, Tempe, AZ 85281, USA
}

diabetes prevention in the ACT NOW study (NEJM 364:1104-1115, 2011). Cox proportional hazard regression was used to compare time to development of diabetes over a mean of 2 years between older ( $\geq 61$ years) and younger participants. We compared effects of

\author{
M. A. Banerji \\ Department of Medicine Division of Endocrinology, State \\ University of New York Downstate Medical Center, 450 Clarkson \\ Ave, Brooklyn, NY 11203, USA \\ G. A. Bray \\ Pennington Biomedical Research Center, Louisiana State \\ University, Baton Rouge, LA 70803, USA \\ T. A. Buchanan \\ Department of Medicine Division of Endocrinology and Diabetes, \\ University of Southern California, Los Angeles, CA, USA \\ R. R. Henry $\cdot$ S. Mudaliar \\ Department of Medicine Division of Endocrinology and \\ Metabolism, University of California San Diego, 9500 Gilman Dr, \\ La Jolla, CA 92093, USA
}

A. E. Kitabchi · F. B. Stentz

Department of Medicine Division of Endocrinology, Diabetes and Metabolism, University of Tennessee Health Science Center, 920 Court Ave, Memphis, TN 38163, USA

P. D. Reaven

Phoenix Veterans Affairs Health Care System, 650 E Indian School Rd, Phoenix, AZ 85012, USA 
pioglitazone versus placebo on metabolic profiles, inflammatory markers, adipokines, $\beta$ cell function (disposition index), insulin sensitivity (Matsuda index), and body composition by ANOVA. Diabetes incidence was reduced by $85 \%$ in older and $69 \%$ in younger subjects $(p=0.41)$. $\beta$ cell function (disposition index) increased by $35.0 \%$ in the older and $26.7 \%$ in younger subjects $(p=0.83)$. Insulin sensitivity (Matsuda index) increased by 3.07 (5.2-fold) in older and by 2.54 (3.8-fold) in younger participants $(p=0.58)$. Pioglitazone more effectively increased adiponectin in older versus younger subjects $(22.9 \pm 3.2 \mu \mathrm{g} / \mathrm{mL}$ [2.7-fold] vs. $12.7 \pm 1.4 \mu \mathrm{g} /$ $\mathrm{mL}$ [2.2-fold], respectively; $p=0.04)$. Younger subjects tended to have a greater increase in whole body fat mass compared to older subjects (3.6 vs. $3.1 \mathrm{~kg} ; p=0.061$ ). Younger and older subjects had similar decreases in bone mineral density $(0.018 \pm 0.0071 \mathrm{vs}$. $0.0138 \pm 0.021 \mathrm{~g} / \mathrm{cm}^{2}$ ). Younger and older pre-diabetic adults taking pioglitazone had similar reductions in conversion to diabetes and older adults had similar or greater improvements in metabolic risk factors, demonstrating that pioglitazone is useful in preventing diabetes in older adults.

Keywords Geriatrics · Diabetes · Prevention · Endocrinology

\section{Background}

The prevalence of diabetes increases dramatically with age and it is estimated that 25-30\% of individuals over the age of 65 have type 2 diabetes (Centers for Disease Control and Prevention 2014). Impaired glucose tolerance (IGT) also is highly prevalent in older adults, affecting $\sim 35 \%$ of individuals $>65$ years (Cowie et al. 2009). Further, individuals with IGT are at high risk of converting to diabetes (5-10\% per year) (Tabak et al. 2012) and manifest similar pathophysiologic disturbances to individuals with type 2 diabetes (DeFronzo 2009). Diabetes is a major contributor to adverse health outcomes with aging (Blaum et al. 2003) and is a significant predictor of disability (Gregg et al. 2000) and frailty (Espinoza et al. 2012), both of which pose significant public health burdens. Therefore, interventions to prevent or delay diabetes in older adults are important in improving aging outcomes as the numbers of older adults who either are living with diabetes or are at risk of developing diabetes increases (Sloan et al. 2008).
Lifestyle modification and some anti-diabetic agents (metformin, acarbose, liraglutide) have been useful in preventing diabetes in prediabetic adults at high risk of developing diabetes (Chiasson et al. 2002; DeFronzo et al. 2011; Diabetes Prevention Program Research Group 2002; Pi-Sunyer et al. 2015). Thiazolidinediones also delayed diabetes progression among subjects with IGT in three placebo-controlled multicenter trials (Buchanan et al. 2002; DeFronzo et al. 2011; DREAM Trial Investigators et al. 2006). In the ACT NOW Study, pioglitazone reduced the conversion of IGT to diabetes by $72 \%$ (DeFronzo et al. 2011).

To design and apply strategies to prevent type 2 diabetes in older adults, it is necessary to determine whether interventions that delay diabetes in the general population are equally effective as people age. A secondary analysis of the Diabetes Prevention Program (DPP) showed that older adults (ages 60 to 85 years) were more responsive to intensive lifestyle intervention than to metformin, compared to younger adults (ages 25 to 59) (Diabetes Prevention Program Research Group 2006), as determined by oral glucose tolerance testing. These findings were thought to be, in part, related to the greater weight loss and more active participation in lifestyle modification activities among older participants and possibly related to differences in the pathophysiology of insulin resistance in aging individuals (Basu et al. 2003).

The goal of the present study was to evaluate whether aging modifies the effectiveness of pioglitazone for the prevention of diabetes. For this purpose, we compared responses between older (ages 61 through 86 years) and younger (ages 18 through 60 years) subjects in the ACT NOW trial.

\section{Methods}

Subjects Subjects were 602 participants from the ACT NOW trial aged 18 or older. We selected the cut point of ages 61 through 86 years for the older group and ages 18 through 60 years for the younger group because age 61 corresponds to the top 25 th percentile for age distribution in this study sample. Patients were eligible for the ACT NOW study if they had a fasting plasma glucose concentration between 95 and $125 \mathrm{mg} / \mathrm{dl}(5.3$ and $6.9 \mathrm{mmol} / \mathrm{l}$ ) and at least one other risk factor for diabetes (DeFronzo et al. 2009). All subjects had IGT, defined as 
a 2-h plasma glucose between 140 and $199 \mathrm{mg} / \mathrm{dl}$ [7.8 to $11.0 \mathrm{mmol} / \mathrm{l}$ ] during a single oral glucose tolerance test (OGTT) (American Diabetes Association 2008) as published previously (DeFronzo et al. 2009, 2011). The first participant was recruited in January 2004 , and enrollment was completed in March 2006. Participants were followed until they reached the primary end point of diabetes, withdrew from the study, were lost to follow-up, or completed the study.

Study design The study design and protocol have been described previously (DeFronzo et al. 2009). Briefly, eight centers participated in this investigator-initiated study, which was approved by the Institutional Review Board at each site. Written informed consent was obtained from all participants. All results were transmitted to the Data Coordinating Center in Phoenix, Arizona, where they were recorded and audited and then sent to the Data Analysis Center in San Antonio. Takeda Pharmaceuticals provided financial support for the study but had no access to the data. After eligibility for the study was ascertained, participants underwent randomization according to center and sex. Subjects received $30 \mathrm{~min}$ of dietary instruction consistent with the goals of the DPP (Diabetes Prevention Program Research Group 2002).

After enrollment, participants were asked to fast overnight and a 75-g OGTT was performed at $\sim 8$ a.m. the next day. Plasma samples were collected every $15 \mathrm{~min}$ for $2 \mathrm{~h}$ for measurement of plasma glucose and insulin concentrations. Additional baseline assessments included measurements of blood pressure, height, weight, waist circumference, hemoglobin A1c (HbA1c), and lipids. Dual-energy X-ray absorptiometry (DEXA) scans were performed using a Hologic QDR 4500A instrument (Watertown, MA, USA) as previously described (Bray et al. 2013). Five of the eight study centers participated in the DEXA substudy, which had 232 participants.

Following completion of the OGTT, participants received pioglitazone $30 \mathrm{mg} /$ day or a placebo. After 1 month, the dose of pioglitazone was increased to $45 \mathrm{mg}$ /day as tolerated. Participants returned at 2, 4, 6, 8,10 , and 12 months during the first year of the study and every 3 months thereafter. At each visit, weight, blood pressure, and pulse were measured and the extent of edema was graded as described (DeFronzo et al. 2011). Fasting plasma glucose was measured at each follow-up visit. HbA1c and plasma lipids were measured every 6 months, and the OGTT was repeated annually. Plasma C-reactive protein (CRP), monocyte chemotactic protein (MCP)-1, plasminogen-activating inhibitor (PAI)-1, tumor necrosis factor (TNF)- $\alpha$, interleukin (IL)-6, leptin, and adiponectin were measured at baseline and at study end.

Conversion of impaired glucose tolerance to diabetes The primary outcome was the development of diabetes (defined as a fasting plasma glucose level $\geq 126 \mathrm{mg} / \mathrm{dl}[\geq 7.0 \mathrm{mmol} / \mathrm{l}]$ or a 2 -h glucose level $\geq 200 \mathrm{mg} / \mathrm{dl}[11.1 \mathrm{mmol} / \mathrm{l}]$ ); a repeat OGTT was performed to confirm the diagnosis. If the diagnosis was not confirmed, participants continued their assigned therapy.

Calculations Insulin sensitivity (Matsuda index) was derived from plasma glucose and insulin measurements obtained during the OGTT as previously described (Matsuda and DeFronzo 1999). $\beta$ cell function was determined with the insulin secretion/insulin resistance (disposition) index calculated as $\left(\Delta^{\mathrm{I}} 0-120 / \Delta^{\mathrm{G}} 0\right.$ $120) \times$ (Matsuda index) during the OGTT, where $\Delta^{\mathrm{I}} 0$ $120 / \Delta^{\mathrm{G}} 0-120$ represents the increment in plasma insulin and glucose concentrations during the 120-min OGTT (Abdul-Ghani et al. 2006). Plasma glucose, insulin, lipids, HbA1c, CRP, MCP-1, PAI-1, TNF- $\alpha$, IL- 6 , leptin, and adiponectin were measured as previously described (DeFronzo et al. 2013, 2009).

Statistical analysis Baseline characteristics were examined by age group (stratified according to age: $\geq 61$ years vs. $<61$ ) using chi-squared tests for categorical variables and $t$ tests for continuous variables. Linear regression analysis was used to examine study outcomes in response to pioglitazone versus placebo at study end by age group. Outcomes assessed were change in insulin sensitivity (Matsuda index), fasting plasma glucose, fasting insulin, lipids, HbAlc, adipokines, and markers of inflammation. Additional regression analyses were performed with covariate adjustment for sex and baseline value of each individual outcome (i.e., change in adiponectin was adjusted for sex and baseline adiponectin value). Log transformation was used for non-normally distributed outcome variables. Cox proportional hazard models were used to examine time to diabetes conversion by age category. These analyses were adjusted for sex and baseline measures. 


\section{Results}

Subject characteristics Baseline data stratified by age and treatment assignment are shown in Table 1. There were no significant differences between groups in either the young or older participants for any characteristics. Overall, regardless of treatment assignment, older participants were more likely to be female (56 vs. $36 \%$, $p<0.001$ ), but did not differ by race or ethnic group compared to younger participants. At baseline, older participants had lower BMI $(32.5 \pm 5.0 \mathrm{vs}$. $\left.35.0 \pm 6.5 \mathrm{~kg} / \mathrm{m}^{2}, p<0.0001\right)$, higher systolic blood pressure $(134 \pm 16$ vs. $126 \pm 16 \mathrm{mmHg}, p<0.0001)$, lower fasting insulin $(8.9 \pm 8.3$ vs. $11.4 \pm 9.1 \mu \mathrm{U} / \mathrm{mL}$, $p<0.001)$, lower LDL cholesterol (99 \pm 28 vs. $108 \pm 31 \mathrm{mg} / \mathrm{dL}, p=0.001)$, higher HDL cholesterol ( $42 \pm 11$ vs. $40 \pm 10 \mathrm{mg} / \mathrm{dl}, p=0.007)$, and lower total cholesterol $(166 \pm 33$ vs. $173 \pm 35 \mathrm{mg} / \mathrm{dL}, p=0.028)$ compared to younger participants. Overall, compared to younger participants, older participants had slightly higher insulin sensitivity as measured by the Matsuda index at baseline $(4.4 \pm 2.7$ vs. $3.8 \pm 2.7$, $p=0.0008$ ).

There were no significant differences in plasma inflammatory biomarkers between pioglitazone and placebo groups in the young versus older age groups. However, older participants had higher plasma IL-6 $(4.7 \pm 18.0$ vs. $4.4 \pm 35.4 \mathrm{pg} / \mathrm{mL}, p=0.030), \mathrm{MCP}-1$ $(158 \pm 64$ vs. $130 \pm 54 \mathrm{pg} / \mathrm{mL}, p<0.0001), \mathrm{TNF}-\alpha$ $(4.8 \pm 1.8$ vs. $3.9 \pm 2.8 \mathrm{pg} / \mathrm{mL}, p<0.0001)$, and adiponectin $(13.0 \pm 7.6$ vs. $11.1 \pm 7.2 \mu \mathrm{g} / \mathrm{mL}$, $p=0.0011)$ concentration at baseline. There were no overall age differences in circulating levels of leptin, PAI-1, or CRP compared with younger participants.

Baseline body composition and bone density data for participants in the DEXA substudy are shown in Supplemental Table 1. Older subjects had higher whole body fat percentage $(41.9 \pm 6.2$ vs. $38.8 \pm 7.8 \%$, $p=0.023)$ and lower bone mineral density $\left(0.95 \pm 0.09\right.$ vs. $\left.1.02 \pm 0.11 \mathrm{~g} / \mathrm{cm}^{2}, p=0.0025\right)$ compared to younger participants.

Effect of treatment on conversion to diabetes As previously reported, pioglitazone reduced the incidence of diabetes by $72 \%$ overall $(\mathrm{HR}=0.28,95 \%$ CI $0.16-$ $0.49 ; p<0.001)(10)$. After adjustment for age and sex, this finding did not change significantly (HR $=0.29,95 \%$ CI $0.16-0.49 ; p<0.01)$. In older participants, diabetes incidence was reduced by $84 \%$
$(\mathrm{HR}=0.16,95 \%$ CI $0.05-0.50 ; p<0.01) ;$ and in younger subjects diabetes incidence was reduced by $69 \%(\mathrm{HR}=0.31,95 \%$ CI $0.17-0.57, p<0.01)$ (Fig. 1). Diabetes incidence did not differ by age $(p=0.41)$.

Effect of pioglitazone on laboratory and physiologic parameters As previously reported, pioglitazone reduced fasting plasma glucose, insulin, hemoglobin A1c, triglycerides, PAI-1, IL-6, TNF- $\alpha$ and increased insulin sensitivity, plasma high density lipoprotein (HDL), and adiponectin in the overall cohort (DeFronzo et al. 2013, 2011; Saremi et al. 2013). For all indices in the unadjusted analyses, older and younger adults responded similarly to pioglitazone (Fig. 2 and Supplemental Table 3). However, in analyses adjusted for sex and baseline value, adiponectin was increased more in older compared to younger subjects taking pioglitazone $(22.94 \pm 3.19 \mu \mathrm{g} / \mathrm{mL}$ [2.72-fold increase] vs. $12.70 \pm 1.43 \mu \mathrm{g} / \mathrm{mL}$ [2.23-fold increase], $p=0.04)$. In pioglitazone-treated subjects, $\beta$ cell function (disposition index) increased by 0.98 (1.2-fold) in older adults $(p=0.08)$ and by $1.2(1.19$-fold $)$ in younger subjects $(p<0.01)$. There was no difference in response by age group $(p=0.74)$. Pioglitazone improved insulin sensitivity (Matsuda index) in the overall cohort (DeFronzo et al. 2011). The Matsuda index of insulin sensitivity increased to 3.07 (5.2-fold increase) in older adults taking pioglitazone versus placebo $(p<0.01)$ and to 2.54 (3.8-fold increase) in younger subjects $(p<0.01)$; however, there was no significant difference in increased insulin sensitivity in older versus younger subjects taking pioglitazone $(p=0.58)$.

Body composition Pioglitazone increased whole body fat mass in the overall ACT NOW cohort (Bray et al. 2013), and the increment from baseline in body fat was similar in younger (by $3.62 \pm 0.63 \mathrm{~kg}$ [2.6-fold], $p<0.001$ ) and older (by $3.10 \pm 1.6 \mathrm{~kg}$ [2.6-fold], $p=0.061)$ subjects ( $p=0.751$ between groups) (Supplemental Table 3). Pioglitazone reduced total body bone mineral density in the overall cohort (Bray et al. 2013). The decrease in total bone mineral density with pioglitazone was similar in younger (by $0.018 \pm 0.0071 \mathrm{~g} / \mathrm{cm}^{2}, p=0.013$ ) and older (by $\left.0.0138 \pm 0.021 \mathrm{~g} / \mathrm{cm}^{2}, p=0.521\right)$ subjects. However, this effect did not differ by age group ( $p=0.835$ between groups). 
Table 1 Characteristics by treatment and age groups at study baseline

\begin{tabular}{|c|c|c|c|c|c|c|c|c|}
\hline & \multicolumn{3}{|c|}{ Young age $<61$} & \multicolumn{3}{|c|}{ Older age $\geq 61$} & \multirow[b]{2}{*}{$\begin{array}{l}\text { Total } \\
N=602 \\
N(\%) \text { or } \\
\text { mean (SD) }\end{array}$} & \multirow[b]{2}{*}{$\begin{array}{l}p \text { value age difference } \\
\text { (young vs. old) }^{\mathrm{a}}\end{array}$} \\
\hline & $\begin{array}{l}\text { Pioglitazone } \\
N=214 \\
N(\%) \text { or } \\
\text { mean (SD) }\end{array}$ & $\begin{array}{l}\text { Placebo } \\
N=220 \\
N(\%) \text { or } \\
\text { mean (SD) }\end{array}$ & $\begin{array}{l}p \\
\text { value }\end{array}$ & $\begin{array}{l}\text { Pioglitazone } \\
N=88 \\
N(\%) \text { or } \\
\text { mean (SD) }\end{array}$ & $\begin{array}{l}\text { Placebo } \\
N=80 \\
N(\%) \text { or } \\
\text { mean (SD) }\end{array}$ & $\begin{array}{l}p \\
\text { value }\end{array}$ & & \\
\hline Age & $47.4(8.6)$ & $46.2(9.2)$ & 0.083 & $65.9(4.9)$ & $66.3(4.9)$ & 0.637 & $52.3(11.8)$ & $<0.0001$ \\
\hline Race & & & 0.240 & & & 0.809 & & \\
\hline White & $161(75.2)$ & $178(80.9)$ & & $72(81.8)$ & $67(83.8)$ & & 478 (79.4) & 0.8094 \\
\hline Black & $44(20.6)$ & $34(15.5)$ & & $13(14.8)$ & $11(13.8)$ & & $102(16.9)$ & \\
\hline Asian & $5(2.3)$ & $8(3.6)$ & & $2(2.3)$ & $2(2.5)$ & & $17(2.8)$ & \\
\hline Pacific Islander & $1(0.5)$ & $0(0.0)$ & & $0(0.0)$ & $0(0.0)$ & & $1(0.2)$ & \\
\hline Native American & $2(0.9)$ & $0(0.0)$ & & $1(1.1)$ & $0(0.0)$ & & $3(0.5)$ & \\
\hline Other & $1(0.5)$ & $0(0.0)$ & & $0(0.0)$ & $0(0.0)$ & & $1(0.2)$ & \\
\hline Sex, female & $80(37.4)$ & $78(35.5)$ & 0.676 & $47(53.4)$ & $47(58.8)$ & 0.486 & $252(41.9)$ & $<0.001$ \\
\hline Pioglitazone group & & & & & & & $302(50.2)$ & 0.5583 \\
\hline BMI $\left(\mathrm{kg} / \mathrm{m}^{2}\right)$ & $34.6(6.4)$ & $32.3(6.7)$ & 0.333 & $32.5(5.1)$ & $32.5(5.0)$ & 0.996 & $34.3(6.2)$ & $<0.0001$ \\
\hline Body surface area $\left(\mathrm{m}^{2}\right)$ & $2.1(0.3)$ & $2.1(0.3)$ & 0.317 & $2.1(0.2)$ & $2.1(0.2)$ & 0.471 & $2.10(0.25)$ & 0.0710 \\
\hline Waist circumference $(\mathrm{cm})$ & $106.3(14.1)$ & $\begin{array}{l}107.7 \\
(15.1)\end{array}$ & 0.347 & $106.0(11.4)$ & $\begin{array}{r}105.9 \\
(13.4)\end{array}$ & 0.957 & $\begin{array}{l}106.7 \\
(14.0)\end{array}$ & 0.4220 \\
\hline $\begin{array}{l}\text { Systolic blood pressure } \\
(\mathrm{mmHg})\end{array}$ & $125.7(16.3)$ & $\begin{array}{l}125.5 \\
(15.8)\end{array}$ & 0.893 & $131.5(15.5)$ & $\begin{array}{l}136.4 \\
\quad(16.3)\end{array}$ & 0.047 & $128(16)$ & $<0.0001$ \\
\hline $\begin{array}{l}\text { Diastolic blood pressure } \\
(\mathrm{mmHg})\end{array}$ & $74.5(9.9)$ & $74.0(10.4)$ & 0.578 & $72.4(8.1)$ & $74.2(10.2)$ & 0.220 & $74(10)$ & 0.3395 \\
\hline $\begin{array}{l}\text { Fasting plasma glucose (mg/ } \\
\text { dL) }\end{array}$ & $104.7(7.9)$ & $104.7(7.9)$ & 0.961 & $104.9(7.0)$ & $104.0(7.1)$ & 0.389 & $105(8)$ & 0.7677 \\
\hline Fasting insulin $(\mathrm{mU} / \mathrm{mL})$ & $11.1(8.2)$ & $11.6(9.9)$ & 0.565 & $9.1(9.1)$ & $8.8(7.5)$ & 0.835 & $10.7(8.9)$ & $<0.001$ \\
\hline Hemoglobin A1c (\%) & $5.5(0.4)$ & $5.5(0.4)$ & 0.741 & $5.6(0.5)$ & $5.5(0.4)$ & 0.130 & $5.5(0.4)$ & 0.126 \\
\hline $\begin{array}{l}\text { Hemoglobin A1c } \\
\quad(\mathrm{mmol} / \mathrm{mol})\end{array}$ & 36 & 36 & & 38 & 36 & & 36 & \\
\hline Triglycerides (mg/dL) & $125.8(63.5)$ & $\begin{array}{l}119.1 \\
(56.0)\end{array}$ & 0.253 & $118.0(47.3)$ & $\begin{array}{l}123.9 \\
(65.4)\end{array}$ & 0.506 & $122(59)$ & 0.9569 \\
\hline Total cholesterol (mg/dL) & $171.0(34.6)$ & $\begin{array}{l}173.9 \\
\quad(35.5)\end{array}$ & 0.400 & $162.6(32.4)$ & $\begin{array}{l}168.8 \\
\quad(33.6)\end{array}$ & 0.229 & $171(35)$ & 0.0282 \\
\hline HDL cholesterol (mg/dL) & $39.7(10.3)$ & $39.7(10.1)$ & 0.978 & $41.3(11.6)$ & $43.5(10.9)$ & 0.210 & $40(11)$ & 0.0073 \\
\hline LDL cholesterol (mg/dL) & $106.2(30.7)$ & $\begin{array}{r}110.3 \\
(31.8)\end{array}$ & 0.178 & $97.7(29.2)$ & $\begin{array}{r}101.1 \\
(28.0)\end{array}$ & 0.454 & $\begin{array}{l}105.8 \\
\quad(30.8)\end{array}$ & 0.0012 \\
\hline Matsuda index & $3.7(2.6)$ & $3.8(2.6)$ & 0.894 & $4.4(2.5)$ & $4.4(3.0)$ & 0.914 & $3.9(2.6)$ & 0.0008 \\
\hline Disposition index & $3.2(1.9)$ & $3.2(1.9)$ & 0.933 & $3.4(1.6)$ & $3.4(1.5)$ & 0.865 & $3.23(1.79)$ & 0.1206 \\
\hline $\begin{array}{l}\text { Glucose area under the curve } \\
\text { during } 120 \text { min OGTT }\end{array}$ & $1.1(0.6)$ & $1.1(0.7)$ & 0.913 & $1.0(0.6)$ & $1.0(0.6)$ & 0.440 & $1.05(0.6)$ & 0.1599 \\
\hline IL-6 (pg/mL) & $7.2(50.4)$ & $1.7(1.6)$ & 0.188 & $7.2(24.9)$ & $2.1(1.4)$ & 0.121 & $4.5(31.3)$ & 0.0304 \\
\hline Leptin $(\mathrm{pg} / \mathrm{mL})$ & $35.6(23.1)$ & $36.7(25.7)$ & 0.719 & $34.2(26.3)$ & $34.8(27.9)$ & 0.908 & $35.7(25.2)$ & 0.086 \\
\hline MCP-1 (pg/mL) & $136.9(56.6)$ & $\begin{array}{l}123.7 \\
(51.4)\end{array}$ & 0.038 & $156.4(71.4)$ & $\begin{array}{l}159.2 \\
(55.8)\end{array}$ & 0.811 & $138(59)$ & $<0.0001$ \\
\hline $\mathrm{TNF}-\alpha(\mathrm{pg} / \mathrm{mL})$ & $4.2(3.7)$ & $3.7(1.6)$ & 0.152 & $4.9(1.9)$ & $4.7(1.6)$ & 0.506 & $4.2(2.6)$ & $<0.0001$ \\
\hline Adiponectin $(\mu \mathrm{g} / \mathrm{mL})$ & $11.0(6.7)$ & $11.1(7.8)$ & 0.860 & $12.6(7.0)$ & $13.6(8.2)$ & 0.454 & $11.7(7.4)$ & 0.0011 \\
\hline PAI-1 (ng/mL) & $15.1(8.8)$ & $15.9(8.3)$ & 0.400 & $15.1(12.2)$ & $13.6(5.9)$ & 0.404 & $15.2(8.9)$ & 0.288 \\
\hline CRP (mg/L) & $3.4(3.9)$ & $3.1(3.8)$ & 0.695 & $4.9(4.9)$ & $2.7(2.9)$ & 0.264 & $3.4(3.9)$ & 0.9667 \\
\hline
\end{tabular}

${ }^{\mathrm{a}} p$ value for age difference between young and older participants across treatment groups 
Fig. 1 Kaplan-Meier curve for time to conversion to diabetes by treatment group (pioglitazone vs. placebo) and age group (age $\geq 61$ vs. $<61$ years)

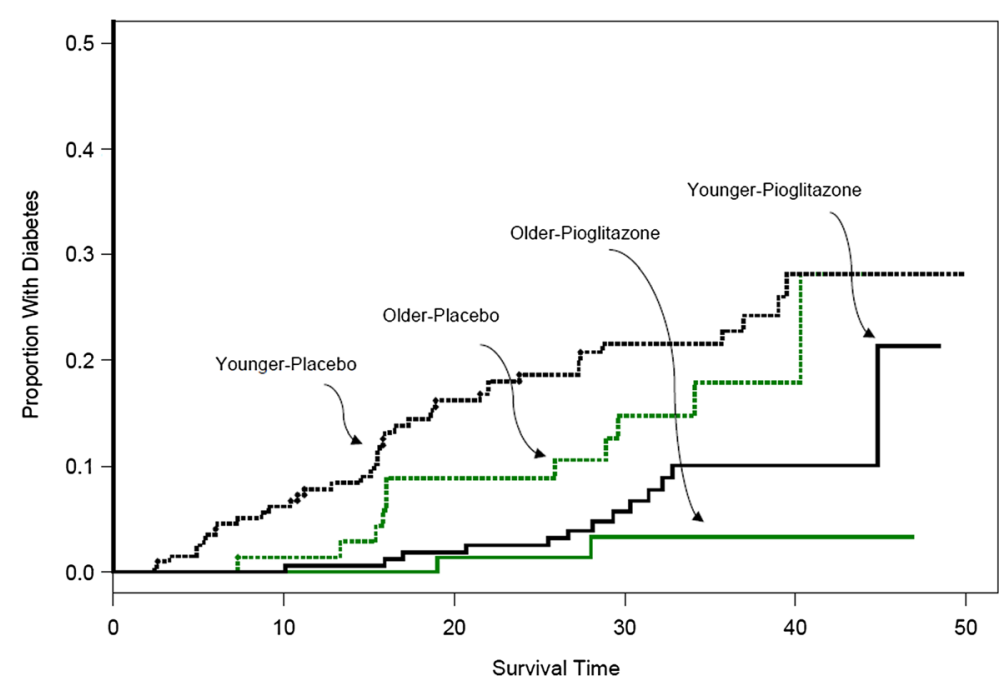

Adverse events Adverse events were low in both groups (Supplemental Table 4). No differences between groups were seen with respect to changes in peripheral edema, hematuria, body mass index, waist circumference, or fractures or other adverse events. There were also no age group differences in the incidence of adverse events.

\section{Discussion}

Older adults are at increased risk of developing diabetes, and those with IGT are at the highest risk. In this study, we examined whether the efficacy of pioglitazone for diabetes prevention and metabolic responses differed by age. Overall, older and younger participants had similar responses for most outcomes. Notably, pioglitazone was highly effective in reducing conversion to diabetes in older subjects, similar to responses in younger individuals.

Age-dependent declines in both $\beta$ cell function and insulin sensitivity play major roles in the deterioration of glucose homeostasis that occurs with advancing age (Chang et al. 2006; Ghosh et al. 2011). Pioglitazone is thought to improve $\beta$ cell function and ameliorate insulin resistance through its action on the peroxisome proliferator-activated receptor (PPAR)- $\gamma$ (DeFronzo et al. 2013). We previously showed that the risk of developing diabetes in the ACT NOW Study was closely related to waning $\beta$ cell function as determined by the insulin secretion/insulin resistance (IS/IR) index and that an improved IS/IR index with pioglitazone was the strongest predictor for reduced risk of conversion to diabetes. In the present study, the IS/IR index improved similarly in older and younger adults. Thus, while $\beta$ cell function seems to decline progressively with advancing age (Chang et al. 2006), $\beta$ cells from older participants still responded appropriately to the PPAR- $\gamma$ agonist. Similarly, in older and younger subjects, pioglitazone was equally effective in improving insulin sensitivity, a major factor contributing to diabetes prevention (DeFronzo et al. 2009, 2011).

While lifestyle intervention remains the preferred initial recommendation for subjects with pre-diabetes and was highly effective in the DPP, not all older adults can achieve the goals of lifestyle intervention due to chronic disease, pain, and/or disability. Therefore, many older adults with pre-diabetes remain at risk for diabetes despite lifestyle intervention; in such people, pharmacotherapy for diabetes prevention may be appropriate. However, it remains unknown whether older adults with pre-diabetes are appropriate candidates for preventative pharmacotherapies - and among those therapies, which are most effective in preventing diabetes in older adults.

Current clinical guidelines from the American Diabetes Association and the American Geriatrics Society do not recommend pharmacologic agents for diabetes prevention in prediabetic adults over 60 years old (American Diabetes Association 2014). This recommendation results, in part, from a subanalysis of the DPP study which showed that, although older and younger adults responded to metformin, intensive lifestyle modification was significantly more effective than metformin in improving glucose tolerance with advancing age, as assessed by OGTT (Diabetes Prevention Program Research Group 2006). However, when conversion of pre-diabetes to 
a

Disposition Index

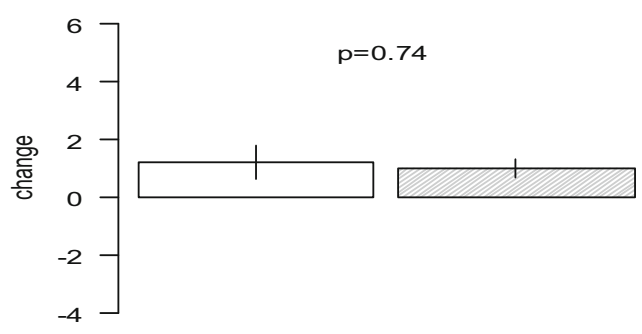

C

HbA1c

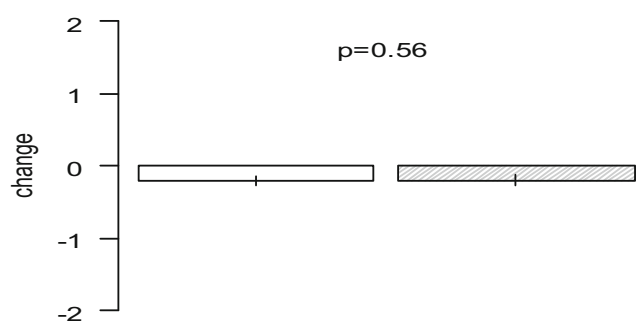

e

DBP

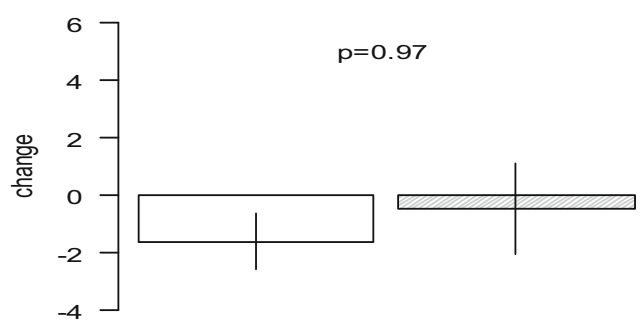

g

Total Body Fat Mass

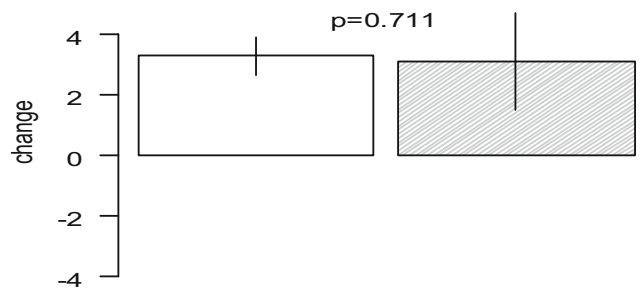

Fig. 2 Change with pioglitazone compared to placebo in: a disposition index, b Matsuda index, $\mathbf{c}$ hemoglobin A1c (HBA1c), d adiponectin, e diastolic blood pressure(DBP), f systolic blood preassure (SBP), $\mathbf{g}$ total body fat mass, $\mathbf{h}$ total bone mineral

diabetes was determined by an $\mathrm{HbA} 1 \mathrm{c} \geq 6.5 \%$, metformin was equally effective in older and younger subjects (Diabetes Prevention Program Research Group 2015). These data (Diabetes Prevention Program Research Group 2002; Sloan et al. 2008), along with the results presented here, indicate that both pioglitazone and b

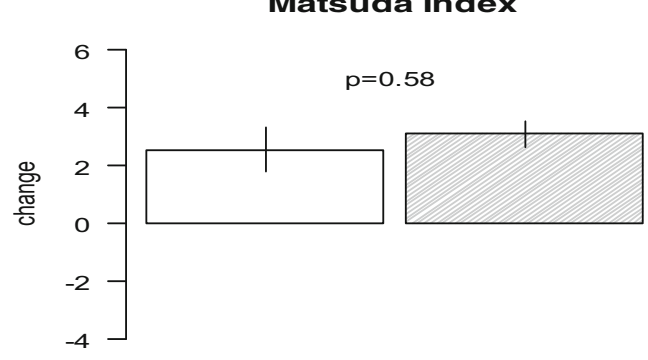

d

Adiponectin

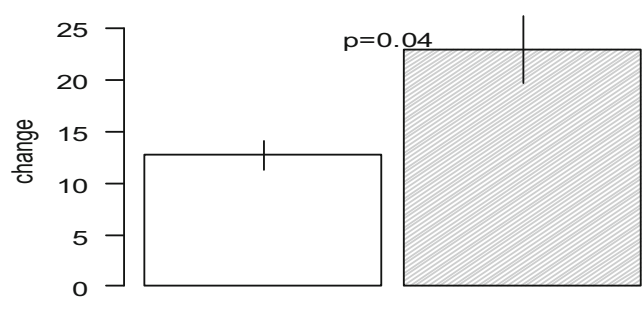

$\mathbf{f}$

SBP

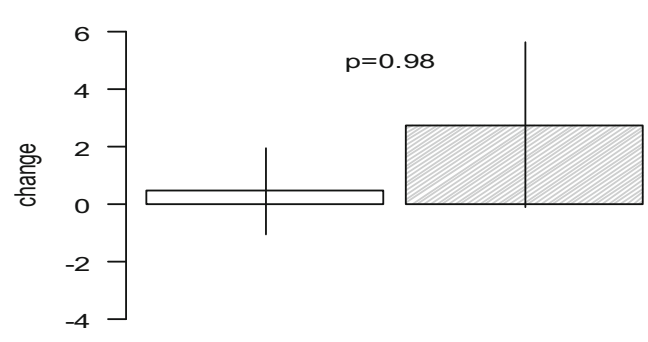

h

Total Bone Mineral Density

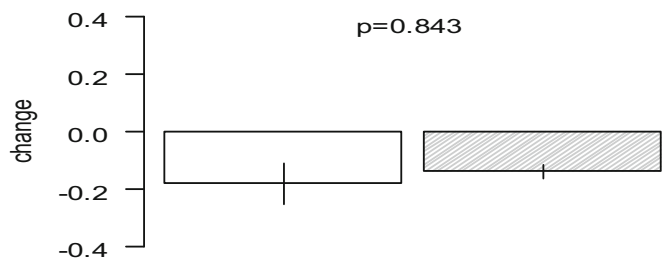

density by age group. The open boxes indicate the younger age group (age $<61$ years) and the filled boxes represent the older age group (age $\geq 61$ years)

metformin offer an alternative to delay/prevent diabetes in older subjects at high risk of developing diabetes.

It remains to be determined whether metformin might be preferable as a preventive therapy in older adults because of its other potentially beneficial anti-aging properties. Clinical trials are needed to address this 
question. However, evidence from animal studies suggests that metformin has aging-modulating properties such as lifespan extension (Martin-Montalvo et al. 2013), improved exercise tolerance and healthspan (Martin-Montalvo et al. 2013), and reduced incidence of cancer (Berstein 2012; DeCensi et al. 2010).

The incidence of adverse events was similar in both age groups for all outcomes. In ACT NOW, pioglitazone was associated with a small decrease in bone mineral density in the pelvis in men and women and decreased bone mineral density in the thoracic spine and ribs of women and in the lumbar spine and legs of men. However, the rate of fractures was similar in pioglitazone versus placebo groups (Bray et al. 2013; DeFronzo et al. 2011). Another study indicated that thiaozolidinediones increase fracture risk in postmenopausal women but not men (Zhu et al. 2014). Until there is more clarity about the interplay between aging, bone loss, and thiaozolidinediones, these agents should be used with caution in older subjects, particularly women.

Many issues need to be resolved before advocating routine use of thiaozolidinediones for diabetes prevention in older subjects. First, there is no evidence that pharmacologic treatment of pre-diabetes/impaired glucose tolerance or mild diabetes in older subjects improves overall morbidity and mortality. Second, the potential toxicity and adverse effects of thiaozolidinediones in older adults remain unclear. In addition to reduced bone density and possible increases in fracture risk, edema and heart failure are well-known adverse effects of thiaozolidinediones. However, in ACT NOW, overall rates of these adverse effects were low and not affected by age. Moreover, older subjects typically take many drugs, and adding another medication could increase the risk of harmful interactions. Thus, risks/benefits should be carefully assessed in every patient, particularly older adults, before prescribing drugs to prevent and treat mild diabetes (American Geriatrics Society Expert Panel on the Care of Older Adults with Diabetes Mellitus 2013). For example, an older adult who takes few medications and has good functionality and life expectancy, but shows signs of early microvascular damage (i.e., retinopathy or macroalbuminuria), may potentially benefit from an intervention for diabetes prevention/ early treatment. On the other hand, in an older patient with limited life expectancy who is already taking multiple drugs, risks of additional treatment with pioglitazone may outweigh any potential benefit. Most importantly, more research in this area is required in order to make substantiated recommendations.
In summary, older prediabetic adults demonstrated similar reductions in conversion to diabetes and similar or better improvements in metabolic risk factors with pioglitazone compared to younger counterparts. Pioglitazone may be a useful pharmacologic agent to prevent diabetes in older adults.

Acknowledgments This study is supported by an investigatorinitiated and unrestricted research grant from Takeda Pharmaceuticals and grants from the General Clinical Research Center (GCRC) at the University of Tennessee Health Science Center (MO1-RR00221), the National Institutes of Health Clinical and Translational Science Award UL1TR000130 to the University of Southern California, and the South Texas Veterans Health Care System-Audie Murphy Division and the GCRC at the University of Southern California Keck School of Medicine (MO1-RR-00043) and by the Veterans Affairs institutions in Phoenix and San Diego, which contributed their resources and the use of their facilities. Sara Espinoza, Nicolas Musi, Devjit Tripathy, and Ralph A. DeFronzo are supported, in part, by the South Texas Veterans Health Care System.

Compliance with ethical standards Briefly, eight centers participated in this investigator-initiated study, which was approved by the Institutional Review Board at each site. Written informed consent was obtained from all participants.

Conflict of interest Dr. DeFronzo reports being on advisory boards for Astra Zeneca, Novo Nordisk, Janssen, Boehringer-Ingelheim, Intarcia, speaker bureaus for Novo-Nordisk and Astra Zeneca. Dr. DeFronzo also receives research support from Boehringer-Ingelheim, Takeda, Astra Zeneca, and Janssen. Dr. Reaven reports research support from Astra Zeneca and Novo Nordisk. Dr. Henry reports serving as consultant for Alere, Intarcia, Ionis, Johnson \& Johnson/Janssen, and Sanofi-Aventis and serves on the advisory boards for AstraZeneca, Boehringer Ingelheim, Elcelyx, Intarcia, Johnson \& Johnson/Janssen., Novo Nordis, and Sanofi-Aventis. Dr. Henry also receives research support from Hitachi, Eli Lilly, and Viacyte. No other potential conflict of interests were reported.

Open Access This article is distributed under the terms of the Creative Commons Attribution 4.0 International License (http:// creativecommons.org/licenses/by/4.0/), which permits unrestricted use, distribution, and reproduction in any medium, provided you give appropriate credit to the original author(s) and the source, provide a link to the Creative Commons license, and indicate if changes were made.

\section{References}

Abdul-Ghani M, Jenkinson C, Richardson D, Tripathy D, DeFronzo R (2006) Insulin secretion and action in subjects with impaired fasting glucose and impaired glucose tolerance: results from the Veterans Administration Genetic Epidemiology Study. Diabetes 55:1430-1435 
American Diabetes Association (2008) Diagnosis and classification of diabetes mellitus. Diabetes Care (Suppl 1):S55-S60

American Diabetes Association (2014) Standards of medical care in diabetes - 2014. Diabetes Care 37(Supp 1):S14

American Geriatrics Society Expert Panel on the Care of Older Adults with Diabetes Mellitus (2013) Guidelines abstracted from the American Geriatrics Society Guidelines for improving the care of older adults with diabetes: 2013 update. J Am Geriatr Soc 61:2020-2026

Basu R, Breda E, Oberg A, Powell C, Man C, Basu A, Vittone J, Klee G, Arora P, Jensen M, et al. (2003) Mechanisms of the age-associated deterioration in glucose tolerance. Diabetes 52:1738-1748

Berstein LM (2012) Metformin in obesity, cancer and aging: addressing controversies. Aging (Albany NY) 4:320-329

Blaum CS, Ofstedal MB, Langa KM, Wray LA (2003) Functional status and health outcomes in older Americans with diabetes mellitus. J Am Geriatr Soc 51:745-753

Bray GA, Smith SR, Banerji MA, Tripathy D, Clement SC, Buchanan TA, Henry RR, Kitabchi AE, Mudaliar S, Musi $\mathrm{N}$, et al. (2013) Effect of pioglitazone on body composition and bonde density in subjects with prediabetes in the ACT NOW trial. Diabetes, Obesity \& Metabolism 15:931-937

Buchanan TA, Xiang AH, Peters RK, Kjos SL, Marroquin A, Goico J, Ochoa C, Tan S, Berkowitz K, Hodis HN, Azen SP (2002) Preservation of pancreatic beta-cell function and prevention of type 2 diabetes by pharmacological treatment of insulin resistance in high-risk Hispanic women. Diabetes 9:2796-2803

Centers for Disease Control and Prevention (2014) National Diabetes Statistics Report: estimates of diabetes and its burden in the United States

Chang A, Smith M, Galecki A, Bloem C, Halter J (2006) Impaired beta-cell function in human aging: response to nicotinic acidinduced insulin resistance. J Clin Endocrinol Metab 91: 3303-3309

Chiasson JL, Josse RG, Gomis R, Hanefield M, Karasik A, Laakso M, STOP-NIDDM Trail Research Group (2002) Acarbose for prevention of type 2 diabetes mellitus: the STOP-NIDDM randomised trial. Lancet 359:2072-2077

Cowie C, Rust K, Ford E, Eberhardt M, Byrd-Holt D, Li C, Williams D, Gregg E, Bainbridge K, Saydah S, Geiss L (2009) Full accounting of diabetes and pre-diabetes in the U.S. population in 1988-1994 and 2005-2006. Diabetes Care 32:287-294

DeCensi A, Puntoni M, Goodwin P, Cazzinga M, Gennari A, Bonanni B, Gandini S (2010) Metformin and cancer risk in diabetic patients: a systematic review and meta-analysis. Cancer Prev Res 3:1451-1461

DeFronzo RA (2009) Banting Lecture. From the triumvirate to the ominous octet: a new paradigm for the treatment of type 2 diabetes mellitus. Diabetes 58:773-795

DeFronzo R, Banerji M, Bray G, Buchanan T, Clement S, Henry R, Kitabchi A, Mudaliar S, Musi N, Ratner R, et al. (2009) Actos now for the prevention of diabetes (ACT NOW) study. BMC Endocr Disord 9:17

DeFronzo R, Tripathy D, Schwenke D, Banerji M, Bray G, Buchanan T, Clement S, Gastaldelli A, Henry R, Kitabchi A, et al. (2013) Prevention of diabetes with pioglitazone in ACT NOW: physiologic correlates. Diabetes 62:3920-3926
DeFronzo RA, Tripathy D, Schwenke DC, Banerji M, Bray GA, Buchanan TA, Clement SC, Henry RR, Hodis HN, Kitabchi AE, et al. (2011) Pioglitazone for diabetes prevention in impaired glucose tolerance. N Engl J Med 364:1104-1115

Diabetes Prevention Program Research Group (2002) Reduction in the incidence of type 2 diabetes with lifestyle intervention or metformin. N Engl J Med 346(6):393-403

Diabetes Prevention Program Research Group (2006) The influence of age on the effects of lifestyle modification and metformin in prevention of diabetes. J Gerontol A Med Sci 61A(10):1075-1081

Diabetes Prevention Program Research Group (2015) HbA1c as a predictor of diabetes and as an outcome in the Diabetes Prevention Program: a randomized clinical trial. Diabetes Care 38:51-58

DREAM Trial Investigators, Gerstein HC, Yusuf S, Bosch J, Pogue J, Sheridan P, Dinccag N, Hanefield M, Hoogwerf B, Laakso M, et al. (2006) Effect of rosiglitazone on the frequency of diabetes in patients with impaired glucose tolerance or impaired fasting glucose: a randomised controlled trial. Lancet 368:1096-1105

Espinoza SE, Jung I, Hazuda H (2012) Frailty transitions in the San Antonio longitudinal study of aging. J Am Geriatr Soc 60:652-660

Ghosh S, Lertwattanarak R, Lefort N, Molina-Carrion M, JoyaGaleana J, Bowen BP, Garduno-Garcia Jde J, Abdul-Ghani M, Richardson A, DeFronzo RA, et al. (2011) Reduction in reactive oxygen species production by mitochondria from elderly subjects with normal and impaired glucose tolerance. Diabetes 60:2051-2060

Gregg EW, Beckles GL, Williamson DF, Leveille SG, Langlois JA, Engelgau MM, Narayan KM (2000) Diabetes and physical disability among older U.S. adults. Diabetes Care 23: $1272-1277$

Martin-Montalvo A, Mercken E, Mitchell S, Palacios H, Mote P, Scheibye-Knudsen M, Gomes A, Ward T, Minor R, Blouin M, et al. (2013) Metformin improves healthspan and lifespan in mice. Nature Commun 4:2192

Matsuda M, DeFronzo RA (1999) Insulin sensitivity indices obtained from oral glucose tolerance testing: comparison with the euglycemic insulin clamp. Diabetes Care 22:1462-1470

Pi-Sunyer X, Astrup A, Fujioka K, Greenway F, Halpern A, Krempf M, Lau D, le Roux C, Ortiz V, Jensen C, Wilding J, SCALE Obesity and Prediabetes NN8022-1839 Study Group (2015) A randomized, controlled trial of $3.0 \mathrm{mg}$ of liraglutide in weight management. N Engl J Med 373:11-22

Saremi A, Schwenke D, Buchanan T, Hodis H, Mack W, Banerji M, Bray G, Clement S, Henry R, Kitabchi A, et al. (2013) Pioglitazone slows progression of atherosclerosis in prediabetes independent of changes in cardiovascular risk factors. Arterioscler Thromb Vasc Biol 33:393-399

Sloan FA, Bethel MA, Ruiz D, Shea AH, Feinglos MN (2008) The growing burden of diabetes mellitus in the US elderly population. A. M. A. Arch Intern Med 168:192

Tabak A, Herder C, Rathmann W, Brunner E, Kivimaki M (2012) Pre-diabetes: a high-risk state for diabetes development. Lancet 379:2279-2290

Zhu Z, Jiang Y, Ding T (2014) Risk of fracture for thiazolidinediones: an updated meta-analysis of randomized clinical trials. Bone 68:115-123 